\title{
Nutcracker syndrome: diagnosis and therapy
}

\author{
Marcin K. Kolber ${ }^{1}$, Zhonghao Cui ${ }^{2}$, Christine K. Chen ${ }^{1}$, Peiman Habibollahi ${ }^{1}$, Sanjeeva P. Kalva ${ }^{3}$ \\ ${ }^{1}$ Division of Interventional Radiology, Department of Radiology, University of Texas Southwestern Medical Center, Dallas, TX, USA; ${ }^{2}$ University of \\ Texas Southwestern School of Medicine, Dallas, TX, USA; ${ }^{3}$ Division of Interventional Radiology, Department of Radiology, Massachusetts General \\ Hospital, Boston, MA, USA \\ Contributions: (I) Conception and design: MK Kolber, S Kalva; (II) Administrative support: MK Kolber, S Kalva; (III) Provision of study materials or \\ patients: All authors; (IV) Collection and assembly of data: MK Kolber, Z Cui, S Kalva; (V) Data analysis and interpretation: MK Kolber, Z Cui, S \\ Kalva; (VI) Manuscript writing: All authors; (VII) Final approval of manuscript: All authors. \\ Correspondence to: Marcin K. Kolber, MD. Division of Interventional Radiology, Department of Radiology, University of Texas Southwestern \\ Medical Center, 5323 Harry Hines Blvd, Dallas, TX 75390-8834, USA. Email: Marcin.Kolber@UTSouthwestern.edu.
}

\begin{abstract}
Nutcracker syndrome (NCS) is an extrinsic compression of the left renal vein (LRV) by the superior mesenteric artery (SMA) anteriorly and aorta posteriorly resulting in renal vascular congestion manifesting as hematuria, proteinuria, orthostatic hypotension, pain, or even renal dysfunction. Longstanding venous compression can encourage collateral drainage pathways through gonadal and pelvic veins, which may explain reported symptom and syndrome overlap with pelvic congestion syndrome. Diagnosis can be challenging and variable, frequently involving a combination of ultrasound Doppler, cross-sectional, and invasive imaging. Often, intravascular pressure measurements are required to prove a renocaval pressure gradient to aid in a definitive diagnosis. Conservative management is appropriate, especially in children, who tend to outgrow the disorder. In the interim, medical management with angiotensin converting enzyme inhibitors (ACEIs) is a useful therapy to manage orthostatic hypotension in the pediatric population. In adults, invasive therapies are more frequently pursued. These are aimed at relieving the extrinsic compression on the LRV. The standard of care is renal vein transposition, with renal autotransplantation reserved for recalcitrant cases. Endovascular stenting is a less invasive option. Laparoscopic placement of an exovascular stent is a newer therapy intended to minimize trauma to the LRV. In this review, we will discuss the clinical manifestations, diagnostic criterion, imaging features, and conservative and surgical therapies for this condition.
\end{abstract}

Keywords: Nutcracker syndrome (NCS); left renal vein (LRV); vascular compression; hematuria

Submitted Feb 03, 2020. Accepted for publication Aug 04, 2020.

doi: $10.21037 / \mathrm{cdt}-20-160$

View this article at: http://dx.doi.org/10.21037/cdt-20-160

\section{Introduction}

Nutcracker syndrome (NCS) was first coined in 1972 (1) to describe the effect of a narrow angle between the superior mesenteric artery (SMA) and aorta compressing the left renal vein (LRV), as viewed in the sagittal orientation (Figure 1). An aortomesenteric (AM) angle of <35-39 degrees is generally agreed upon as required for the syndrome to manifest, but NCS is considered a diagnosis of exclusion and various imaging and physiologic metrics are utilized for confirmation $(2,3)$. Given the variety of diagnostic criterion, the exact prevalence of NCS is unknown. Peak age of incidence is second decade to middleage (ranging from childhood to seventh decade) (4). Though classically believed to have a slight female predilection (5), more recent studies suggest equal prevalence between genders $(3,4)$.

\section{Etiology}

Classic NCS is infrequently referred to as anterior NCS to differentiate from a less common variant, Posterior 

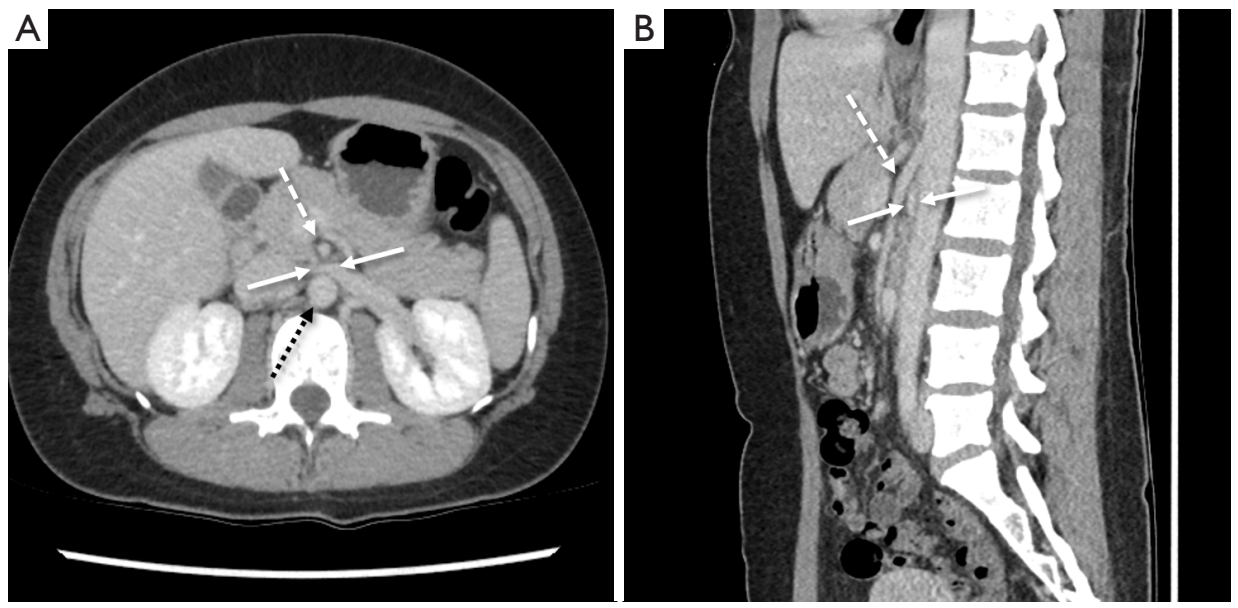

Figure 1 Axial (A) and sagittal (B) venous-phase contrast-enhanced CTA demonstrating compression of the AM segment of the LRV (white arrow) between the SMA (dashed white arrow) and aorta (dotted black arrow). CTA, computed tomography angiography; AM, aortomesenteric; LRV, left renal vein; SMA, superior mesenteric artery.

NCS, which occurs in the presence of a retroaortic LRV compressed by the vertebral column posteriorly and aorta anteriorly $(6,7)$, but results in similar symptoms. Combined (anterior and posterior) NCS has also been reported, resulting from a circumaortic or duplicated LRV with both components stenosed by extrinsic compression (8). Still rarer etiologies of LRV compression include compression by adjacent lymphadenopathy or malignancy (9), severe lordosis (10), pregnancy (11), intestinal malrotation (12), and rapid weight loss (13).

NCS has a suspected correlation to low body mass index (BMI), with some authors noting that symptoms resolve with increasing BMI (14). One explanation is a lack of supporting mesenteric fat, which otherwise lifts the bowel and raises the angle of the SMA. Another suggestion is a correlation to renal ptosis, a condition in which the kidney descends within the retroperitoneum upon position change from supine to upright, has been implicated in LRV "stretching" over the aorta and subsequent venous congestion (15). A lack of supporting retroperitoneal fat in these patients may contribute to renal "descent" (16).

\section{Clinical manifestations}

The hallmark manifestations of NCS-hematuria, proteinuria, and flank/pelvic pain (3)-are probably related to renal venous congestion and increased pressure within the communicating venous structures. Within the renal collecting system, periureteral and peripelvic varices engorge and rupture, resulting in macroscopic or microscopic hematuria $(17,18)$. Isolated left-sided hematuria, identified on cystoscopy as hematuria from the left ureteral orifice only, supports the diagnosis (19).

Within the nephron, venous hypertension is believed to induce a subclinical immune cascade in the wall of the vessel (20), predisposing to a greater-than-necessary local release of norepinephrine and angiotensin II upon standing (21). This exaggerated physiologic response to abrupt changes in renal hemodynamics is thought to result in orthostatic proteinuria $(22,23)$. However, it should be noted that orthostatic proteinuria is relatively common in the pediatric population as a whole, affecting $2-5 \%$ of children and young adults, most of whom experience a benign course (21). In addition, severe systemic hypertension has been reported in association with NCS (24).

Extrinsic to the kidney, the LRV communicates most directly with the lumbar venous plexus and the left gonadal vein [in addition to the inferior vena cava (IVC)] (Figure 2), which frequently dilate as they emerge as preferential drainage pathways for the renal vein (Figure $3 A$ ) (11). In advanced cases, gonadal vein engorgement can progress to pelvic congestion syndrome (25), a condition defined as noncyclic chronic pelvic pain and/or heaviness attributable to gonadal vein reflux and dilation (Figure 3B) (26). The gonadal vein communicates directly with the ovarian venous plexus and subsequently the uterine venous plexus, eventually draining to the hypogastric vein via visceral tributaries or parietal tributaries via gluteal vulvoperineal 


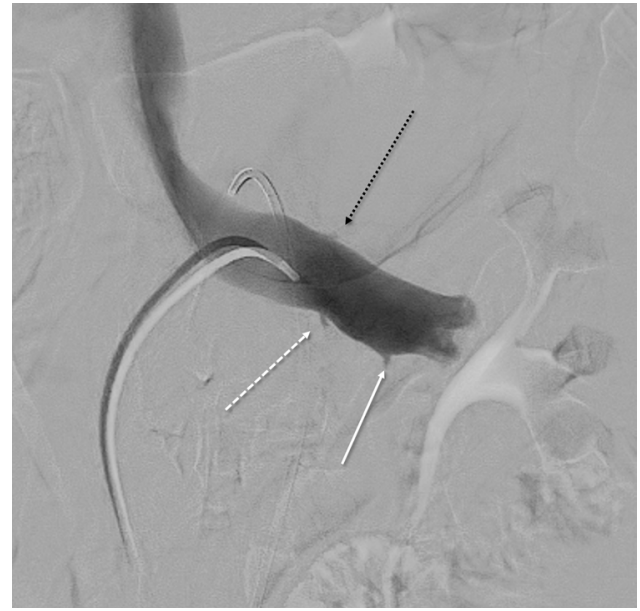

Figure 2 Normal eft renal venography (without evidence of NCS), demonstrating minimal reflux into small-caliber lumbar (solid white arrow), gonadal (dashed white arrow), and adrenophrenic (dotted black arrow) veins. NCS, nutcracker syndrome. veins-any of which may contribute to pain, fullness, or discomfort in the pelvis (27). Concomitant NCS has been described in up to $18 \%$ of patients with pelvic venous congestion syndrome (28). In males, NCS, as diagnosed by elevated LRV velocities, is frequently associated with varicocele caused by venous hypertension and collateralization (Figure 3C) (29).

Another example of symptom and syndrome overlap with NCS is loin pain hematuria syndrome (LPHS), a rare condition characterized by loin pain radiating to the abdomen, medial thigh, and/or groin, with an estimated prevalence of $0.012 \%(30,31)$. It is estimated to be caused by NCS in up to $40 \%$ of patients (32).

\section{Diagnosis}

Even in patients with a straightforward and highly suspicious clinical history, the diagnosis of NCS can be
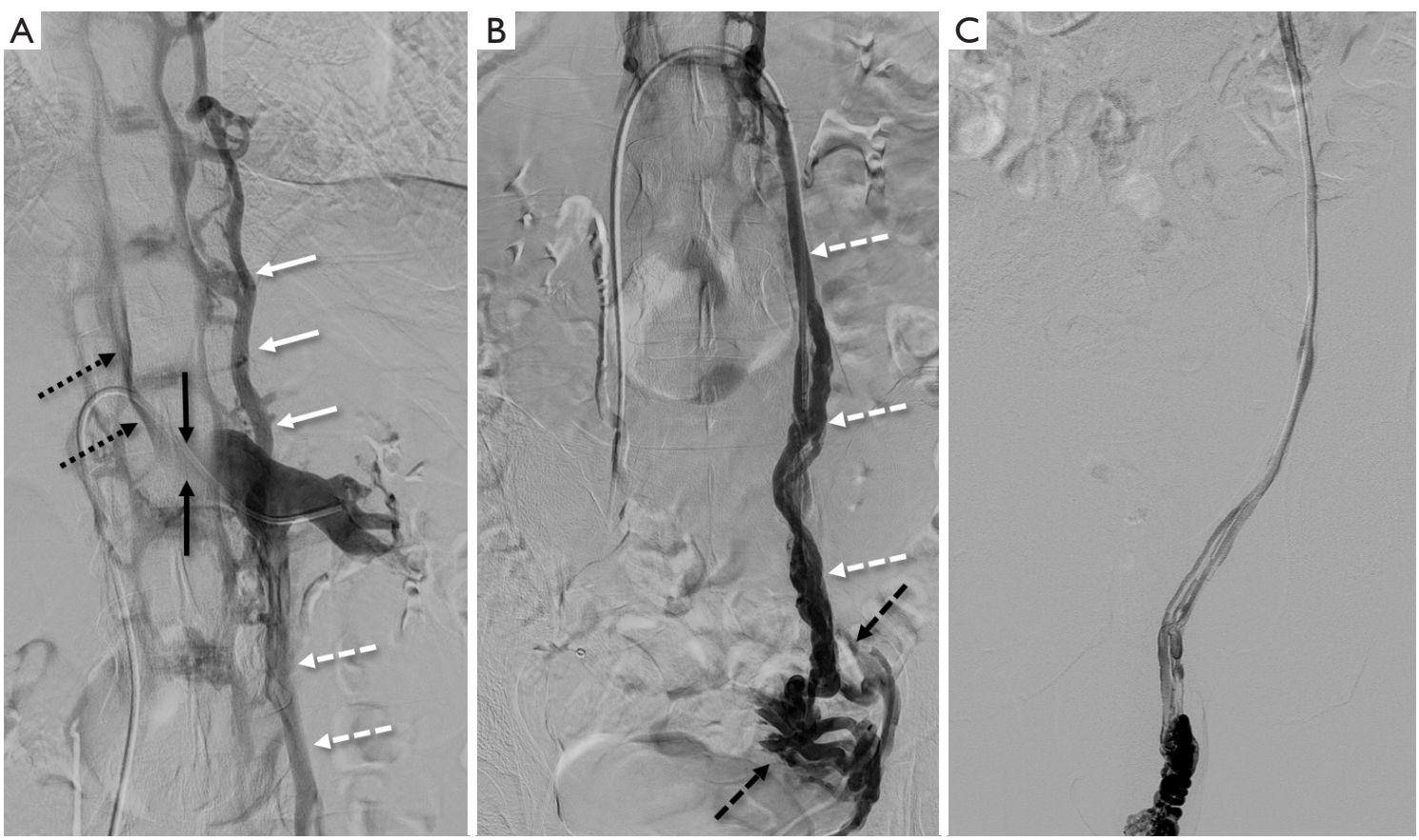

Figure 3 Collateral venous drainage in NCS. (A) Left renal venography in NCS demonstrates poor opacification of the AM LRV (solid black arrows) and IVC (dotted black arrows) with preferential flow via the lumbar venous plexus (solid white arrows) and gonadal vein (dashed white arrows); (B) in females, an enlarged gonadal vein (dashed white arrows) can collateralize with an enlarged uterine venous plexus (dashed black arrows); (C) in males, left renal venous hypertension can contribute to varicocele (shown). NCS, nutcracker syndrome; AM, aortomesenteric; LRV, left renal vein; IVC, inferior vena cava. 

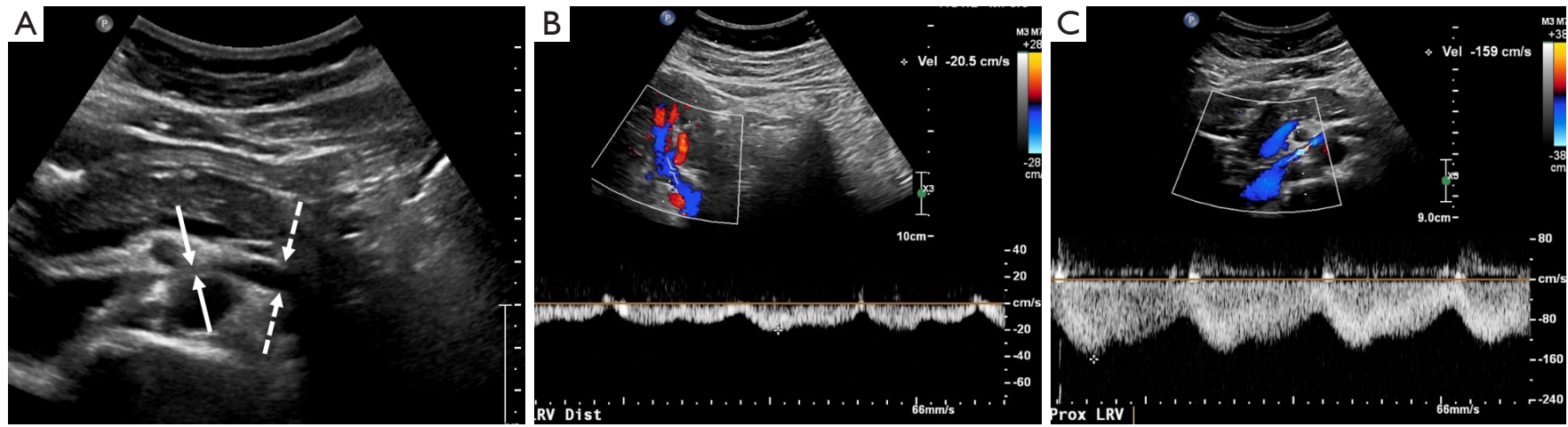

Figure 4 DUS diagnosis of NCS. (A) Grayscale ultrasound identifies the compressed AM segment LRV (solid white arrows) and more peripherally, relative dilation of the more peripheral vein (dashed arrows); (B) DUS at the hilar LRV with low peak velocity (20.5 cm/sec); (C) similar measurements at the aorto-mesenteric segment with high peak velocity $(159 \mathrm{~cm} / \mathrm{sec})$, yielding a ratio of 8:1. DUS, Doppler ultrasound; NCS, nutcracker syndrome; AM, aortomesenteric; LRV, left renal vein.

challenging. Computed tomography (CT), magnetic resonance imaging (MRI) and Doppler ultrasound (DUS) are all reasonable imaging studies in patients with suspected NCS, but frequently invasive assessment with catheter venography and pressure measurement is required for definitive diagnosis (4).

The screening examination of choice is DUS, offering both anatomic and physiologic assessment of the LRV absent radiation. However, the technique can be challenging, requires 6-8 hours fasting, and definitions vary depending on position (supine versus upright) (33). Reference ratios are slightly higher in the upright position, thought to be related to gravity acting on bowel and mesentery, pulling the SMA downward and pronouncing the LRV stenosis. Peak systolic velocity (PSV) is evaluated in the compressed, AM LRV and compared to hilar PSV. Various ratios have been proposed as significant, ranging from 4.0:1 to 5.0:1 (Figure 4) (34-36).

Cross-sectional imaging with CT and MRI relies on vessel diameter and, to a lesser extent, SMA angle to identify pathologic narrowing of the LRV. A normal aortato-SMA angle is between 45 and 90 degrees. An angle of 35 degrees in sagittal dimension suggests NCS (37) (Figure $5 A$ ). In the axial plane, a characteristic "beak" sign with abrupt narrowing of the LRV at the SMA is reported to have a sensitivity of $91.7 \%$ and specificity of $88.9 \%$ (38). As normal absolute values vary by patient, studies have focused on the ratio of diameters of the LRV at the renal hilum as compared to those at the narrowed AM segment. On CT, a hilar-to-AM diameter ratio of $\geq 4.9$ has a $66.7 \%$ sensitivity and $100 \%$ specificity for NCS (Figure 5B) (2).
A separate study demonstrated a $91 \%$ sensitivity and $91 \%$ specificity for NCS with a "compression ratio" of 2.25 , which was described as adequate to raise suspicion for the disease, in the context of symptoms (39). Predictably, higher compression ratios were associated with more symptoms.

MRI is particularly beneficial in children and adolescents owing to the absence of radiation while retaining the ability to evaluate adjacent abnormal vascular structures, such as an enlarged gonadal vein (40). Vein diameter ratios and "beak sign" can be evaluated in similar fashion as CT (Figure 6). A comparison of various MRI sequences determined that True Fast Imaging with Steady-State Free Precession (T2-TRUFI) has particularly good image quality for evaluating the LRV (41). High signal intensity in the LRV on fast-spin-echo T2-weighted sequence due to venous hypertension and stagnation may be particularly useful for diagnosis and evaluating response to therapy (42).

A comparison of DUS (LRV systolic velocity ratios) to CT (vein diameter ratios) demonstrates higher sensitivity and specificity of DUS findings (sensitivity of $80 \% \mathrm{vs}$. $69 \%$; specificity of $94 \%$ vs. $89 \%$, respectively) $(34,36)$. However, invasive testing is frequently pursued for definitive diagnosis, as therapy could require invasive surgery. Venography with direct pressure measurements (Figure 7) (17), with or without intravascular ultrasound (IVUS), is considered the "gold standard" for diagnosis. However, even studies evaluating these methods utilized cystoscopy to confirm isolated left-sided hematuria (2). An elevated pressure gradient between the LRV and the IVC $(\geq 3 \mathrm{mmHg}$ ) is the standard reference point by which venous 

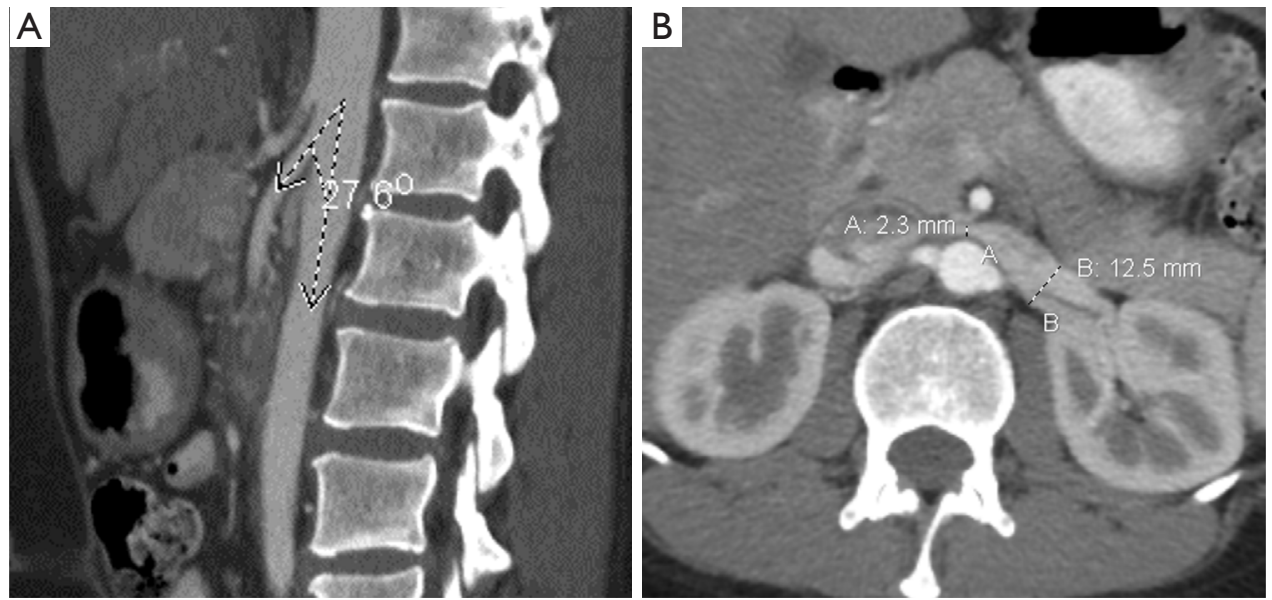

Figure 5 CT diagnosis of NCS. (A) CTA demonstrates an aorta-to-SMA angle of $<35^{\circ}$ in sagittal plane; (B) comparison measurements of aorto-mesenteric $(2.3 \mathrm{~mm})$ to hilar $(12.5 \mathrm{~mm}) \mathrm{LRV}$ in the same patient yields a "compression ratio" of 5.4. CT, computed tomography; NCS, nutcracker syndrome; CTA, computed tomography angiography; SMA, superior mesenteric artery; LRV, left renal vein.
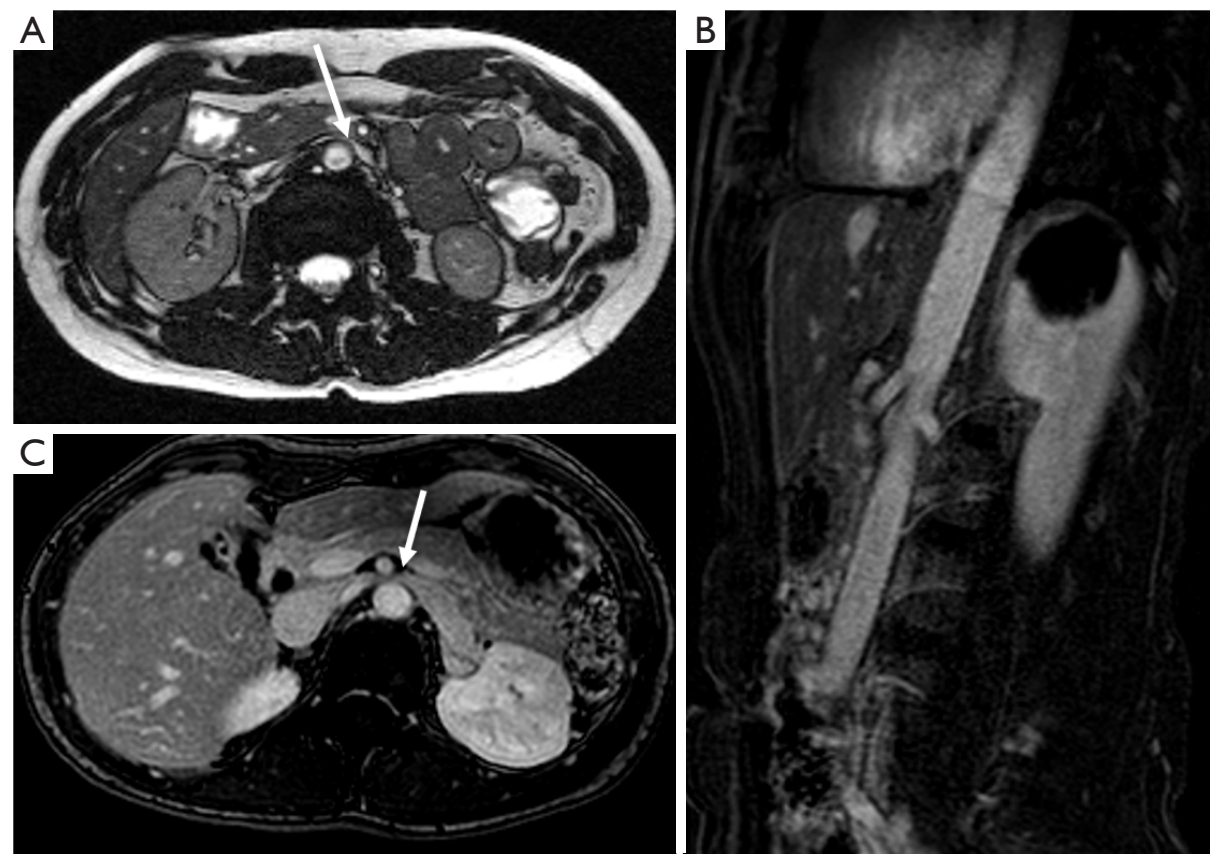

Figure 6 MRI findings in NCS. Axial balanced steady-state gradient echo (A), axial T1 post-contrast mDIXON (B), and obliqued sagittal T1 post-contrast mDIXON (C) sequences demonstrate classic findings of LRV compression with "beak sign" (white arrows) at the aortic margin (MRIs performed in different patients). MRI, magnetic resonance imaging; NCS, nutcracker syndrome; LRV, left renal vein.

hypertension is diagnosed (43). However, it should be noted that some patients may be symptomatic with "compensated" NCS, where compensatory flow through collaterals is large enough that only a borderline renocaval pressure gradient exists (2).

\section{Therapy}

\section{Conservative management}

Conservative management is sufficient in many cases of NCS, most notably in the pediatric population. It is well- 

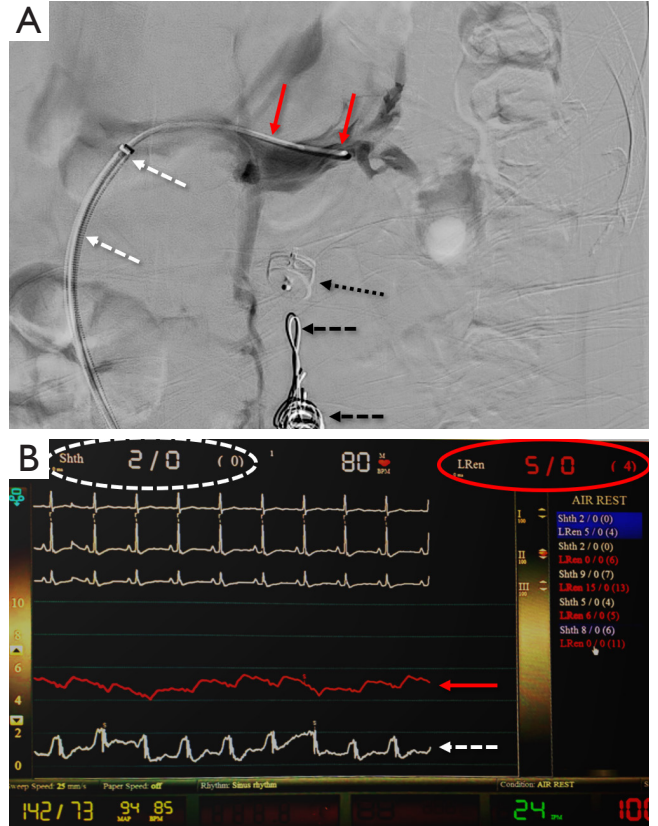

Figure 7 Left renal venography and simultaneous invasive pressure measurements via the vascular sheath in the IVC (dashed white arrows) and catheter in the hilar LRV (solid red arrows). Screenshot of the pressure monitor shows venous pressure waveforms (corresponding arrows) and pressure measurements with mean sheath pressure $0 \mathrm{mmHg}$ and mean left renal catheter pressure $4 \mathrm{mmHg}$ (gradient $=4 \mathrm{mmHg}$ ), diagnostic of NCS. Note a vascular plug (dotted black arrow) and coils (dashed black arrows) in an embolized gonadal vein (common treatment for associated pelvic congestion syndrome). IVC, inferior vena cava; LRV, left renal vein; NCS, nutcracker syndrome.

established that the majority of pediatric patients with NCS will have spontaneous resolution, an effect possibly related to increased retroperitoneal and/or mesenteric adipose during growth and the accumulation of fibrous tissue at the SMA origin. The most widely accepted therapy for the pediatric population is angiotensin converting enzyme inhibitors (ACEIs) to minimize orthostatic proteinuria and treat concomitant hypertension, with or without aspirin, to maximize renal perfusion $(3,44,45)$.

\section{Surgical treatment}

Renal vein transposition is the standard of care for patients with non-remitting symptoms and is the most common invasive intervention for anterior NCS, with excellent immediate and long-term symptom control. The great saphenous vein may be harvested for use as an extension graft or patch onto the LRV if the vein has been damaged by chronic compression. Although a relatively lowrisk procedure, reported complications include paralytic ileus, small bowel adhesion, and LRV restenosis (46). Minimally invasive approaches with laparoscopic or robot assisted-laparoscopic techniques reduced recovery times and are increasingly becoming standard practice $(47,48)$. Nevertheless, re-intervention rates have been reported to be up to $68 \%$, mostly for re-stenosis of the LRV (49).

Left kidney auto-transplantation is also relatively common, though more invasive, as it involves relocating the kidney to the iliac fossa $(10,50)$. This is considered a more thorough approach as it obviates the issue of renal ptosis $(51,52)$. However, the procedure involves a protracted period of renal ischemia, a more extensive dissection, and a total of three anastomoses (artery, vein, and ureter) with consequent possible complications (i.e., stenosis) at any of these sites (16). Nevertheless, auto-transplantation remains a valid option for many patients. In particular, it is utilized in patients who suffer recurrent NCS, or lack of symptoms relief, following LRV transposition (32).

Laparoscopic placement of an extravascular stent (external to the LRV) is a newer means of treating NCS via laparoscopic approach without the need to mobilize or clamp the LRV (Figure 8) (53). A case series of 13 patients reported symptom resolution in 10 and improvement in 2, with one case of stent migration (54). More recently, a 15 -patient cohort that underwent 3D-printed titanium extravascular stent placement were asymptomatic and without restenosis or migration at 24 months (55).

In posterior NCS, because the LRV sits in a retro-aortic space and is compressed between the abdominal aorta and the spine, open surgical transposition of the LRV to an ante-aortic course is preferred. Less common options include transposition of the SMA (which carries a risk mesenteric ischemia), nephropexy with excision of renal varicosities, transposition of the left gonadal vein to the IVC or left common iliac vein, and finally nephrectomy, which is only performed as a last resort in cases where hematuria persists after multiple other attempted procedures $(56,57)$.

\section{Endovascular treatment}

Due to a more minimally invasive nature, endovascular interventions have been applied to the treatment of NCS (Figure 9). Although no dedicated stent system has been developed solely for use in the renal vein, devices already 

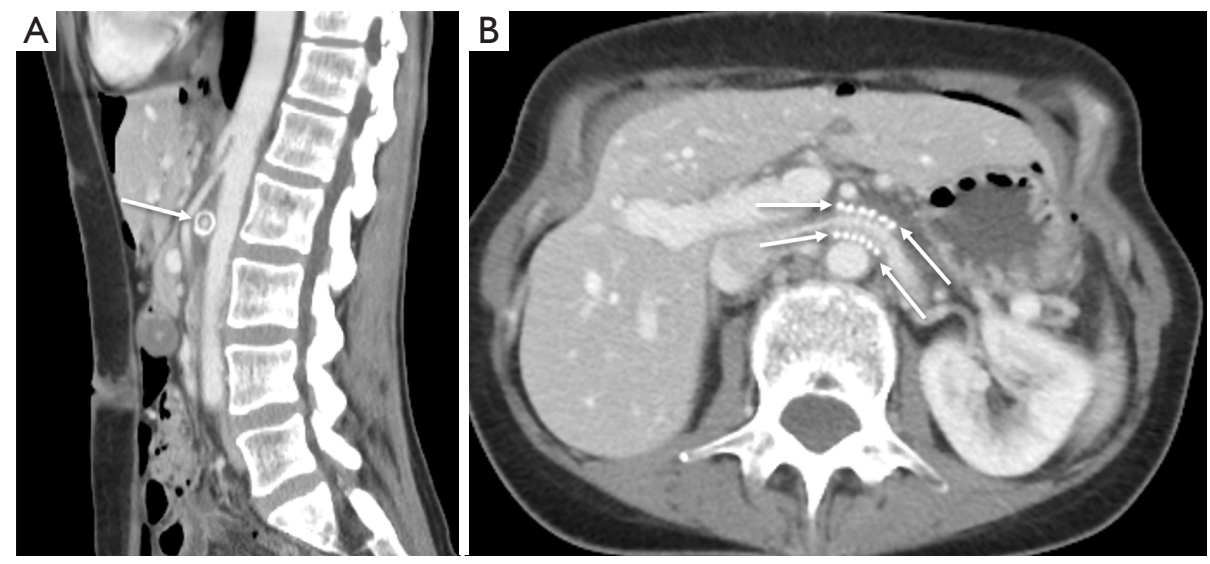

Figure 8 Sagittal (A) and axial (B) CTA following laparoscopic exovascular stent (arrows) placement in a patient with previously diagnosed NCS. CTA, computed tomography angiography; NCS, nutcracker syndrome.
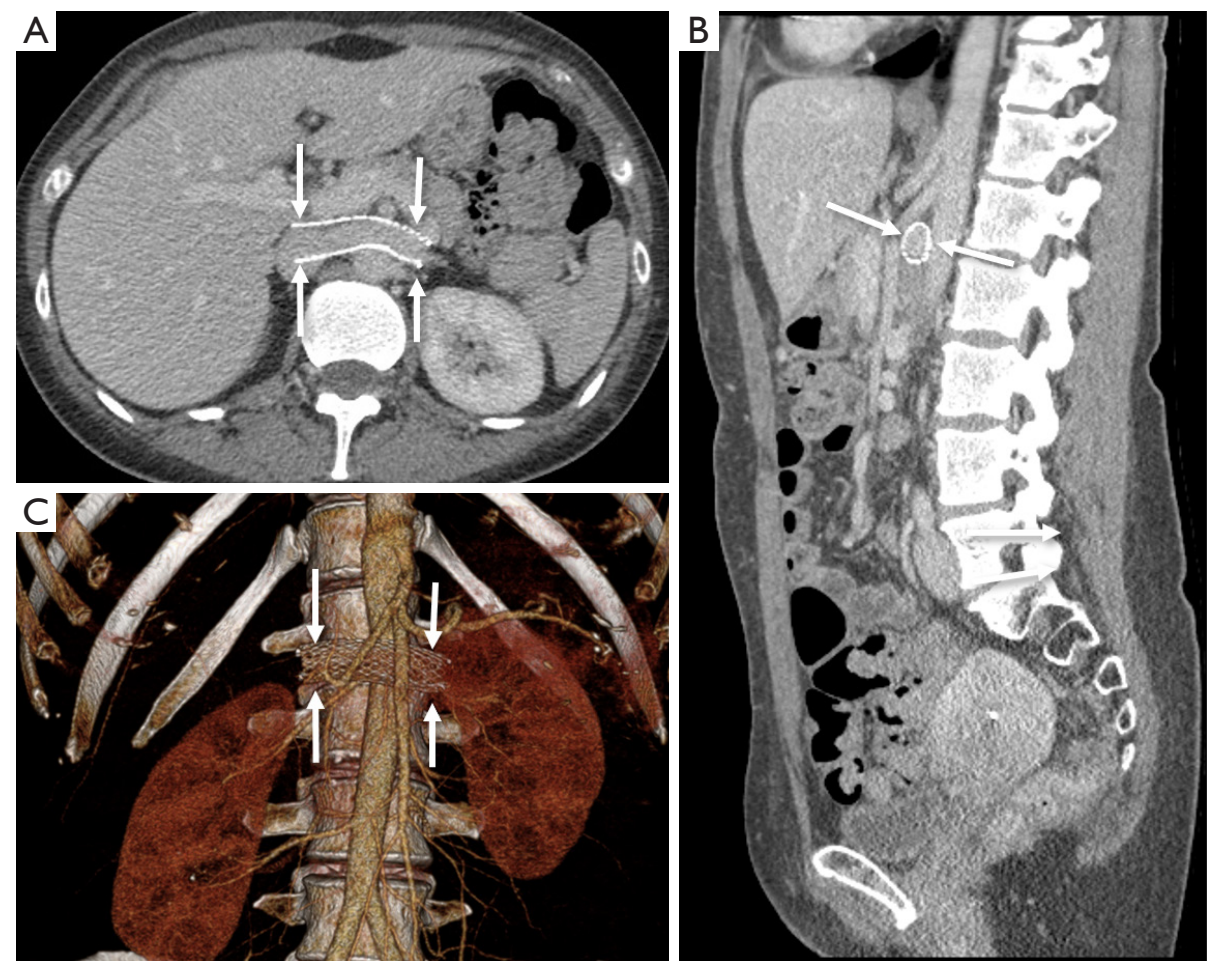

Figure 9 Axial (A), sagittal (B), and 3D-reconstruction (C) CTA following endovascular stent (arrows) deployment in a patient with previously diagnosed NCS. CTA, computed tomography angiography; NCS, nutcracker syndrome.

on the market have been shown to be effective, including SMART Control (Cordis, Santa Clara CA, USA) and Wallstent (Boston Scientific, Marlborough MA, USA) $(46,52,56)$. Though infrequent, endovascular stenting of posterior NCS has also been reported (58). It has been suggested that concomitant use of IVUS allows for more accurate sizing of stents (59). Benefits of this approach include rapid recovery time and symptom resolution. As with any intravascular stent, thrombosis is possible (though rare), and prevention requires anticoagulation and antiplatelet therapy for up to 3 months to allow for stent endothelialization (60). A study of 75 patients undergoing 
LRV stenting with mean 55 months follow-up identified a $6.7 \%$ rate of stent migration, either to the IVC [2], the right heart [2] or retrograde to the renal hilum [1], without significant variances in stent sizing or position to explain cause of migration (61). In a recent review of 18 cases of LRV stenting, primary patency was $85.2 \%$ at 2 years, however of five cases performed for stenosis after LRV transposition, three remained symptomatic despite stenting, suggesting limited utility as a salvage therapy (62).

\section{Conclusions}

NCS is a diagnostic consideration in patients with unexplained hematuria, proteinuria, and pelvic or flank pain. Diagnosis relies on determining the anatomic and physiologic degree of LRV compression between the aorta and SMA. DUS, CT, and MRI can suggest the diagnosis with an LRV hilar-to-AM ratio of $>4-5: 1$. DUS has additional value for determining peak velocity ratios in the same locations. However, venography with IVUS or pressure measurements is frequently required for confirmation. Conservative therapy is often appropriate, especially in children and adolescents, with ACEIs the primary medical therapy for proteinuria. Endovascular, laparoscopic, and open surgical treatments have been utilized successfully for persistent cases. Due to the rarity of the condition, there are no clinical studies comparing treatments, however endovascular and extravascular stenting are promising minimally invasive interventions. Further appraisal of these treatments awaits larger and longer-term studies.

\section{Acknowledgments}

Funding: None.

\section{Footnote}

Provenance and Peer Review: This article was commissioned by the editorial office, Cardiovascular Diagnosis and Therapy for the series "Compressive Vascular Syndromes". The article has undergone external peer review.

Conflicts of Interest: All authors have completed the ICMJE uniform disclosure form (available at http://dx.doi. org/10.21037/cdt-20-160). The series "Compressive Vascular Syndromes" was commissioned by the editorial office without any funding or sponsorship. Drs. MKK and
SK served as the unpaid Guest Editors of the series. Dr. SK serves as an unpaid editorial board member of Cardiovascular Diagnosis and Therapy from May 2019 to Apr 2021. Dr. SK reports personal fees from Medtronic, personal fees from Dova Pharmaceuticals, personal fees from Koo Foundation, Taiwan, personal fees from GE healthcare, personal fees from Springer, personal fees from Elsevier, other from Althea Health Inc, CA, personal fees from Boston Scientific, personal fees from Penumbra, grants from BD, grants from NIH, outside the submitted work. The authors have no other conflicts of interest to declare.

Ethical Statement: The authors are accountable for all aspects of the work in ensuring that questions related to the accuracy or integrity of any part of the work are appropriately investigated and resolved.

Open Access Statement: This is an Open Access article distributed in accordance with the Creative Commons Attribution-NonCommercial-NoDerivs 4.0 International License (CC BY-NC-ND 4.0), which permits the noncommercial replication and distribution of the article with the strict proviso that no changes or edits are made and the original work is properly cited (including links to both the formal publication through the relevant DOI and the license). See: https://creativecommons.org/licenses/by-nc-nd/4.0/.

\section{References}

1. de Schepper A. "Nutcracker" phenomenon of the renal vein and venous pathology of the left kidney. J Belge Radiol 1972;55:507-11.

2. Kim KW, Cho JY, Kim SH, et al. Diagnostic value of computed tomographic findings of nutcracker syndrome: correlation with renal venography and renocaval pressure gradients. Eur J Radiol 2011;80:648-54.

3. Ananthan K, Onida S, Davies AH. Nutcracker syndrome: an update on current diagnostic criteria and management guidelines. Eur J Vasc Endovasc Surg 2017;53:886-94.

4. He Y, Wu Z, Chen S, et al. Nutcracker syndrome--how well do we know it? Urology 2014;83:12-7.

5. Shin JI, Lee JS, Kim MJ. The prevalence, physical characteristics and diagnosis of nutcracker syndrome. Eur J Vasc Endovasc Surg 2006;32:335-6.

6. Lau JL, Lo R, Chan FL, et al. The posterior "nutcracker": hematuria secondary to retroaortic left renal vein. Urology 1986;28:437-9.

7. Shah D, Qiu X, Shah A, et al. Posterior nutcracker 
syndrome with left renal vein duplication: An uncommon cause of hematuria. Int J Surg Case Rep 2013;4:1142-4.

8. Shaper KR, Jackson JE, Williams G. The nutcracker syndrome: an uncommon cause of haematuria. Br J Urol 1994;74:144-6.

9. Hsu CW, Chang MC. Laparoscopic paraaortic lymph node dissection in a patient with nutcracker syndrome for rectal cancer - a video vignette. Colorectal Dis 2019;21:124.

10. Shokeir AA, el-Diasty TA, Ghoneim MA. The nutcracker syndrome: new methods of diagnosis and treatment. Br J Urol 1994;74:139-43.

11. Itoh S, Yoshida K, Nakamura Y, et al. Aggravation of the nutcracker syndrome during pregnancy. Obstet Gynecol 1997;90:661-3.

12. Nishio Y, Kawano Y, Hara S. Nutcracker syndrome complicated with intestinal malrotation. BMJ Case Rep 2019;12:e231230.

13. Camacho Fernández-Pacheco B, López-Tomassetti Fernández E, Hernández Hernández JR. Nutcracker Syndrome Secondary to Bariatric Surgery. Obes Surg 2017;27:3001-3.

14. Shin JI, Park JM, Lee SM, et al. Factors affecting spontaneous resolution of hematuria in childhood nutcracker syndrome. Pediatr Nephrol 2005;20:609-13.

15. Wendel RG, Crawford ED, Hehman KN. The "nutcracker" phenomenon: an unusual cause for renal varicosities with hematuria. J Urol 1980;123:761-3.

16. Reed NR, Kalra M, Bower TC, et al. Left renal vein transposition for nutcracker syndrome. J Vasc Surg 2009;49:386-93; discussion 393-4.

17. Beinart C, Sniderman KW, Saddekni S, et al. Left renal vein hypertension: a cause of occult hematuria. Radiology 1982;145:647-50.

18. Stewart BH, Reiman G. Left renal venous hypertension "nutcracker" syndrome. Managed by direct renocaval reimplantation. Urology 1982;20:365-9.

19. Muraoka N, Sakai T, Kimura H, et al. Rare causes of hematuria associated with various vascular diseases involving the upper urinary tract. Radiographics 2008;28:855-67.

20. Pascarella L, Penn A, Schmid-Schonbein GW. Venous hypertension and the inflammatory cascade: major manifestations and trigger mechanisms. Angiology 2005;56 Suppl 1:S3-10.

21. Mazzoni MB, Kottanatu L, Simonetti GD, et al. Renal vein obstruction and orthostatic proteinuria: a review. Nephrol Dial Transplant 2011;26:562-5.
22. Mahan JD, Turman MA, Mentser MI. Evaluation of hematuria, proteinuria, and hypertension in adolescents. Pediatr Clin North Am 1997;44:1573-89.

23. Oteki T, Nagase S, Hirayama A, et al. Nutcracker syndrome associated with severe anemia and mild proteinuria. Clin Nephrol 2004;62:62-5.

24. Azhar AB, Zeb NT, Shah S, et al. Nutcracker syndrome with hypertension: a case report. Cureus 2019;11:e4781.

25. Ito K, Ookawara S, Ueda $Y$, et al. Nutcracker syndrome with pelvic congestion: a case report. Intern Med 2017;56:2811.

26. Bookwalter CA, VanBuren WM, Neisen MJ, et al. Imaging appearance and nonsurgical management of pelvic venous congestion syndrome. Radiographics 2019;39:596-608.

27. Durham JD, Machan L. Pelvic congestion syndrome. Semin Intervent Radiol 2013;30:372-80.

28. Grimm LJ, Engstrom BI, Nelson RC, et al. Incidental detection of nutcracker phenomenon on multidetector CT in an asymptomatic population: prevalence and associated findings. J Comput Assist Tomogr 2013;37:415-8.

29. Hannick JH, Blais AS, Kim JK, et al. Prevalence, Doppler ultrasound findings, and clinical implications of the nutcracker phenomenon in pediatric varicoceles. Urology 2019;128:78-83.

30. Dube GK, Hamilton SE, Ratner LE, et al. Loin pain hematuria syndrome. Kidney Int 2006;70:2152-5.

31. Taba Taba Vakili S, Alam T, Sollinger H. Loin pain hematuria syndrome. Am J Kidney Dis 2014;64:460-72.

32. Bath NM, Al-Qaoud T, Williams DH, et al. Renal autotransplantation results in pain resolution after left renal vein transposition. J Vasc Surg Venous Lymphat Disord 2019;7:739-41.

33. Takahashi Y, Sano A, Matsuo M. An ultrasonographic classification for diverse clinical symptoms of pediatric nutcracker phenomenon. Clin Nephrol 2005;64:47-54.

34. Kim SH, Cho SW, Kim HD, et al. Nutcracker syndrome: diagnosis with Doppler US. Radiology 1996;198:93-7.

35. Park SJ, Lim JW, Cho BS, et al. Nutcracker syndrome in children with orthostatic proteinuria: diagnosis on the basis of Doppler sonography. J Ultrasound Med 2002;21:39-45; quiz 46.

36. Shin JI, Park JM, Lee JS, et al. Morphologically improved nutcracker syndrome in an 11-year-old girl with hematuria. Pediatr Int 2007;49:677-9.

37. Zhang H, Li M, Jin W, et al. The left renal entrapment syndrome: diagnosis and treatment. Ann Vasc Surg 2007;21:198-203.

38. Gulleroglu K, Gulleroglu B, Baskin E. Nutcracker 
syndrome. World J Nephrol 2014;3:277-81.

39. Hangge PT, Gupta N, Khurana A, et al. Degree of left renal vein compression predicts nutcracker syndrome. J Clin Med 2018;7:107.

40. Ahmed K, Sampath R, Khan MS. Current trends in the diagnosis and management of renal nutcracker syndrome: a review. Eur J Vasc Endovasc Surg 2006;31:410-6.

41. Er A, Uzunlulu N, Guzelbey T, et al. The nutcracker syndrome: The usefulness of different MRI sequences for diagnosis and follow-up. Clin Imaging 2019;55:144-7.

42. Wong HI, Chen MC, Wu CS, et al. The usefulness of fast-spin-echo T2-weighted MR imaging in Nutcracker syndrome: a case report. Korean J Radiol 2010;11:373-7.

43. Takebayashi S, Ueki T, Ikeda N, et al. Diagnosis of the nutcracker syndrome with color Doppler sonography: correlation with flow patterns on retrograde left renal venography. AJR Am J Roentgenol 1999;172:39-43.

44. Miró I, Serrano A, Pérez-Ardavín J, et al. Eighteen years of experience with pediatric nutcracker syndrome: the importance of the conservative approach. J Pediatr Urol 2020;16:218.e1-6.

45. Patel PA, Stojanovic J. Diagnosis and treatment of renovascular disease in children. Semin Roentgenol 2019;54:367-83.

46. de Macedo GL, Dos Santos MA, Sarris AB, et al. Diagnosis and treatment of the Nutcracker syndrome: a review of the last 10 years. J Vasc Bras 2018;17:220-8.

47. Chau AH, Abdul-Muhsin H, Peng X, et al. Roboticassisted left renal vein transposition as a novel surgical technique for the treatment of renal nutcracker syndrome. J Vasc Surg Cases Innov Tech 2018;4:31-4.

48. Yu HW, Chai YJ, Kim SJ, et al. Robotic-assisted modified radical neck dissection using a bilateral axillo-breast approach (robotic BABA MRND) for papillary thyroid carcinoma with lateral lymph node metastasis. Surg Endosc 2018;32:2322-7.

49. Erben Y, Gloviczki P, Kalra M, et al. Treatment of nutcracker syndrome with open and endovascular interventions. J Vasc Surg Venous Lymphat Disord 2015;3:389-96.

50. Chuang CK, Chu SH, Lai PC. The nutcracker syndrome managed by autotransplantation. J Urol 1997;157:1833-4.
51. Avgerinos ED, McEnaney R, Chaer RA. Surgical and endovascular interventions for nutcracker syndrome. Semin Vasc Surg 2013;26:170-7.

52. Velasquez CA, Saeyeldin A, Zafar MA, et al. A systematic review on management of nutcracker syndrome. J Vasc Surg Venous Lymphat Disord 2018;6:271-8.

53. Sorokin I, Nelson J, Rectenwald JE, et al. Robot-assisted laparoscopic extravascular stent for nutcracker syndrome. J Robot Surg 2018;12:561-5.

54. Wang SZ, Zhang WX, Meng QJ, et al. Laparoscopic extravascular stent placement for nutcracker syndrome: a report of 13 cases. J Endourol 2015;29:1025-9.

55. Wang H, Guo YT, Jiao Y, et al. A minimally invasive alternative for the treatment of nutcracker syndrome using individualized three-dimensional printed extravascular titanium stents. Chin Med J (Engl) 2019;132:1454-60.

56. de Macedo GL, Dos Santos MA, Sarris AB, et al. Venous revascularization to treat posterior nutcracker syndrome by transposition of the left gonadal vein: case report. J Vasc Bras 2019;18:e20190037.

57. Park JH, Lee GH, Lee SM, et al. Posterior nutcracker syndrome - a systematic review. Vasa 2018;47:23-9.

58. Rodríguez-Morata A, Robles-Martín ML, Reyes-Ortega JP. Endovascular treatment of posterior nutcracker syndrome with a new autoexpandable stent. J Vasc Surg Venous Lymphat Disord 2019;7:118-21.

59. Neupane S, Ambulgekar N, Edla S, et al. Intravascular ultrasound-guided endovascular stenting of renal vein in nutcracker syndrome. Vasc Endovascular Surg 2018;52:355-6.

60. Chen S, Zhang H, Shi H, et al. Endovascular stenting for treatment of nutcracker syndrome: report of 61 cases with long-term followup. J Urol 2011;186:570-5.

61. Wu Z, Zheng X, He Y, et al. Stent migration after endovascular stenting in patients with nutcracker syndrome. J Vasc Surg Venous Lymphat Disord 2016;4:193-9.

62. Avgerinos ED, Saadeddin Z, Humar R, et al. Outcomes of left renal vein stenting in patients with nutcracker syndrome. J Vasc Surg Venous Lymphat Disord 2019;7:853-9.
Cite this article as: Kolber MK, Cui Z, Chen CK, Habibollahi P, Kalva SP. Nutcracker syndrome: diagnosis and therapy. Cardiovasc Diagn Ther 2021;11(5):1140-1149. doi: 10.21037/ cdt-20-160 